\title{
O lugar da Prática de Ensino na formação inicial do professor de História: um estudo sobre o curso de História da UNESP, campus de Assis.
}

Mariana Reis FEITOSA ${ }^{1}$

\section{RESUMO}

Este artigo tem como objetivo apresentar algumas considerações de uma pesquisa realizada junto ao programa de Mestrado em Educação da Universidade Estadual de Londrina que reflete sobre a formação inicial do professor de História. A literatura indica uma dicotomia estabelecida nos Departamentos de História entre as disciplinas ditas de conteúdo especifico e as pedagógicas - geralmente de responsabilidade das Faculdades de Educação-foi feita uma reflexão a respeito da relação desses departamentos com a formação dos professores. Especial interesse foi dado ao significado que a disciplina de Metodologia e Prática de Ensino / Estágio representa na formação inicial do professor de História. Para tanto, discutimos o significado desta disciplina no curso de História da UNESP-Assis.

Palavras - chave: Formação de professores, Prática de Ensino, Estágio.

Este trabalho é fruto de nossa vivência, em sala de aula, como professora de História, de Ensino Fundamental e Médio, na Rede Estadual, na cidade de São Paulo. Neste período, as dificuldades para relacionar as discussões historiográficas, presentes no curso de História, com os métodos de Ensino foram inúmeras. Além disso, alunos e professores encaravam a História como unicamente o estudo do passado, dos grandes homens e heróis: o conteúdo da disciplina parecia algo totalmente externo à vida deles.

Graduada em História e mestranda em Educação pela Universidade Estadual de Londrina, sob a orientação da Prof. ${ }^{a}$ Dr. ${ }^{a}$ Marlene Rosa Cainelli. 


\section{Mesmo, acreditando que}

a História deve contribuir para a formação do indivíduo comum, que enfrenta um cotidiano contraditório, (...), que recebe informações simultâneas de acontecimentos internacionais, que deve, pelo ensino da História, ter condições de refletir sobre tais acontecimentos, localizá-los em um tempo (...), estabelecer relações entre os diversos fatos de ordem política, econômica e cultural, (...) (SEGAL apud BITTENCOURT, 2002, p.20).

Inúmeras foram às vezes que trabalhamos o conteúdo de forma alienante e decorativa, indo pouco além da voz, lousa, giz, apagador e livro didático.

Com grandes dificuldades no cotidiano escolar e grandes inquietações, decidimos refletir a respeito da formação profissional do professor de História. Entendendo que a disciplina de Metodologia de Prática de Ensino e Estágio Supervisionado nas licenciaturas é crucial para o profissional em formação, pois é a atividade de prática que pode contribuir para que o futuro professor saiba manejar a complexidade escolar e resolver problemas práticos da realidade em que vai atuar, adquirindo ainda, capacidade de refletir sobre sua atuação, decidimos refletir a seu respeito.

Despertou-se, assim, a necessidade de se resgatar, através de uma pesquisa, o percurso da disciplina de Metodologia de Prática de Ensino e Estágio Supervisionado, dentro do curso de licenciatura em História da Universidade Estadual Paulista - campus de Assis - instituição pela qual somos formados.

É preciso dizer que a questão central deste trabalho - 0 significado que da disciplina de Metodologia de Prática de Ensino e Estágio Supervisionado tem na formação inicial do professor de História - nasceu da reflexão sobre nossa própria formação, ou seja, trata-se de uma questão intrínseca à nossa formação, que, inclusive, contribuiu na definição de fontes e metodologia da pesquisa.

A pesquisa investiga a relação dos Departamentos de História com a formação dos professores, visto que a literatura indica uma dicotomia estabelecida nesses departamentos entre as disciplinas ditas de conteúdo especifico das Ciências Humanas e Filosofia, e as pedagógicas geralmente de responsabilidade das Faculdades de Educação.

Villalta, um dos direcionadores de nossa escolha por essa temática põe 
em discussão a não preocupação dos Departamentos de História com a formação dos professores de História. Afirma que nos cursos

(...) estabelece-se uma dicotomia as disciplinas de 'conteúdo'- as oferecidas pelo próprio Departamento e por outros das áreas especificas das Ciências Humanas e da Filosofia - e as de 'instrumentalização tecnológica'- aquelas cursadas nos Departamentos e Faculdades de Educação, as chamadas 'disciplinas pedagógicas' (FENELON apud VILLATA, 1992-3, p.229).

Chama atenção também para a distância existente nos cursos de licenciatura entre as disciplinas pedagógicas e as reais condições em que se desenvolve o processo educativo, questiona a forma de realização do Estágio Supervisionado, reiterando a idéia de pouca ou não preocupação com a formação do professor:

Assim, não se dá a relevância devida à familiarização do aluno (...) [0] ensino de História no $1^{\circ}$ e $2^{\circ}$ graus. (...). 0 estágio é realizado apenas nos últimos períodos; está geralmente sob a jurisdição única do professor de Prática de Ensino; quase nunca ultrapassa o nível de observação da realidade de ensino de $1^{\circ} \mathrm{e} 2^{\circ}$ graus e, quando o faz, implicando o desenvolvimento da atividade de Planejamento de Curso e de Regência de Turmas, não é possível aos professores que o supervisionam dar acompanhamento necessário aos estagiários. (...). Com isso, a prática de ensino, a experiência de ensinar e fazer aprender História, torna-se a grande ausencia do processo de formação do professor. (...)(VILLALTA, 1992-93, p.229230) (grifo nosso)

Outra autora que traz a tona alguns problemas dos cursos de licenciaturas é Cainelli:

quando falamos em licenciaturas é como se falássemos de velhos problemas nunca selecionados: só para citar alguns, desarticulação entre conteúdos específicos e os conteúdos pedagógicos, formação teórica não traduzida na prática, falta de integração entre os Departamentos de História e as Faculdades de Educação, desarticulação entre as diferentes diciplinas nos currículos, baixos salários. 
Pderíamos elencar outros tantos e estaríamos falando de problemas passados e presentes e porque não de problemas futuros. (CAINELLI, 1999, p.143).

Ao discutir a desarticulação entre os conteúdos específicos e os pedagógicos e a falta de integração entre os Departmanetos de História e as Faculdades de Educação, propõe pensarmos a Prática de Ensino como momento de refleção dessas discussões, já que ainda hoje nos cursos de licenciatura, a prática aparece nos últimos anos do curso:

A Prática de Ensino precisa levar os alunos a perceberem que conteúdo específico e pedagógico necessitam caminhar juntos, que um não sobrepõe ao outro e sim completam-se na difícil tarefa de ensinar, de construir conhecimento. É preciso também valorizar os conhecimentos pedagógicos dando a estes corpo sólido, porque a estrutura dos cursos hoje destituem a prática de ensino de conteúdo, conteúdos são os específicos e não os pedagógicos.(CAINELLI, 1999, p.144)

A idéia a ser destacada nesses autores é a de que não há uma integração entre as disciplinas de conteúdo específico das Ciências Humanas e as disciplinas pedagógicas ministradas pelo Departamento de Educação ou de História nos cursos de licenciatruas. Tal ação pode trazer prejuizo à formação final do futuro professor de História.

Ranzi também discute a importância da prática de ensino na formação do professor. Esperando que o professor - estagiário consiga dominar conhcecimentos mínimos de sua área de atuação, saiba quem produziu e como se posicionar sem ingenuidade, frente aos conhecimentos produzidos da História (RANZI, 1999), a autora diz que

(...) a prática de ensino é um momento privilegiado para que (...) [a] experiência na produção do saber escolar possa ser suscitada, discutida, refletida. A atividade de prática deve contribuir também para que o profissional em formação, saiba manejar a complexidade e resolver problemas práticos da realidade em que vai atuar, e adquira a capacidade de refletir sobre a sua atuação. (1999, p.141)

Acreditamos ser preciso buscar uma articulação entre estas (as disciplinas de "conteúdo" e as pedagógicas) para que se possibilitem alternativas às questões do 
difícil cotidiano escolar enfrentado pelo professor. Em nosso entendimento inicial, as disciplinas pedagógicas responsáveis pelas atividades em escolas visando despertar questionamentos de procedimentos didáticos, da qualidade da aprendizagem do aluno e aperfeiçoamento do ensino são unilaterais estando pouco ou artificialmente, envolvidas com as outras disciplinas do curso. (GIESTA, 2002). Assim, a pesquisa foi justificada pela crescente preocupação em articular os cursos de licenciatura a realidade educacional.

Entendendo que o estágio caracteriza-se pela capacidade de propiciar ao aluno uma aproximação à realidade na qual irá atuar, não precisando colocarse no "pólo prático" do curso, mas como uma aproximação à prática, na medida em que será conseqüente à teoria estudada no curso (PIMENTA \& GONÇALVES apud PIMENTA, 2005, p.13-14).

Esperamos ser de importância crucial tentar, se não responder, pelo menos esclarecer as questões ditadas pela prática de ensino em um curso de licenciatura, no momento a disciplina Metodologia de Prática de Ensino e Estágio Supervisionado no curso de História da UNESP-Assis, pois repensar o estágio nos cursos de formação de professores poderá contribuir para a melhoria qualitativa dessa formação. Importante dizer que para nós, o Estágio não será "o salvador do curso", ele precisa ser vinculado às outras disciplinas do curso, podendo clarificar alguns medos e questionamentos do professor recém formado e não solucionar todos os seus problemas, já que a escola atual exige um quadro de reflexão mais dinâmico.

Por todos esses motivos expostos, visando obter dados para uma análise que desperte nos profissionais da área um novo olhar sobre a influência da Disciplina Metodologia de Prática de Ensino e Estágio Supervisionado em sua formação, julgamos importante à efetivação deste estudo.

A constatação destes fatos contribuiu de forma decisiva na formulação da seguinte questão: que significado tem a disciplina de Metodologia de Prática de Ensino e Estágio Supervisionado na formação inicial do professor de História?

Tendo como pano de fundo tais aportes, esta pesquisa teve como objetivo principal conhecer as discussões que estavam sendo desenvolvidas na disciplina Metodologia de Prática de Ensino e Estágio Supervisionado que poderiam contribuir para a formação inicial do professor de História.

Em relação à abordagem metodológica optamos por uma pesquisa 
qualitativa. A pesquisa qualitativa, segundo André (1995, p.17) “(...) não envolve manipulação de variáveis, nem tratamento experimental; é o estudo do fenômeno em seu acontecer natural (...)". Assim a focalizarmos o papel da disciplina Metodologia de Prática de Ensino e Estágio Supervisionado na formação do professor de História, tivemos especial atenção no curso de História da Universidade Estadual Paulista: contexto histórico em que foi estruturado breve histórico de implantação do curso, caracterização deste até as atividades desenvolvidas na disciplina de Metodologia de Prática de Ensino e Estágio Supervisionado- e estruturação do estágio.

Contato com ex-alunos, formados em épocas distintas, para tentar verificar a influência do estágio na formação profissional destes também foi feito: estes dados foram obtidos através de um questionário de coleta de dados. Parte das fontes forma constituídas de pesquisa a documentos institucionais (análise da ementa da disciplina Prática de Ensino e do Estágio Supervisionado, regulamento e planejamento do estágio). Revisão de literatura pertinente ao tema também foi realizada. Nota-se, um plano de trabalho aberto e flexível cujos “(...) focos da investigação vão sendo constantemente revistos, as técnicas de coletas, reavaliadas, os instrumentos, reformulados e os fundamentos teóricos, repensados (...)" (ANDRÉ, 1995, p.30).

Notamos que muitas de nossas indagações e questionamentos a respeito do significado da disciplina Metodologia de Prática de Ensino de História e Estágio Supervisionado na formação de professores também estão presentes, na mentalidade de outros ex-alunos do curso, muitas crítcas são feitas a disciplina. A Universidade ainda discute muito pouco, ou de forma bem sutil a formação de professores, nesse sentido, o estágio supervisionado é deficiente em seu principal propósito: preparação de professores.

$\mathrm{Na}$ pesquisa aos documentos institucionais percebemos algumas modificações na organização da Prática de Ensino, especialmente no que se refere a sua carga horária. No entanto, parece-mos que nem mesmo essas modificações nas polticias educacionais, alterações na legislação, inovações, conseguiram dar um novo prefil ao futuro professor. De que adianta acréscimos na carga horária do estágio, se a maneira como ele é feito não é modificada? É ainda maior a preocupação com do historiador e não do professor.

Voltar o olhar para a forma como a disciplina Metodologia de Prática de 
Ensino e Estágio Supervisionado é entendida nos cursos de formação docente poderia ser uma alternativa para que o futuro professor pudesse avançar na idéia de que dar aula não é simplesmente "transpor" de forma mecânica aos alunos os saberes acadêmicos, outros saberes permeiam o ambiente escolar.

Baseando-se em Barreiro e Gebran acreditamos que

(...) a Prática de Ensino deve propiciar ao aluno não apenas a vivencia de sala de aula, como também o contato com a dinâmica escolar em seus diferentes aspectos, garantindo e permitindo a interação teórico - prática. A partir de observações , relatórios e analise do espaço escolar e da sala de aula, esse preocesso ultrapassa a situação da dinamica ensino - apredizagem, favorecendo os aspectos de reflexão e o desenvolvimento de açoes coletivas e integradoras. Propõe-se que a organização da Prática de Ensino perpasse toda a formação profissional do futuro professor, tendo como referência básica tanto a proposta pedagógica da escola, na qual o futuro docente é supervisionado, quanto os conteúdos a serem ensinados e as políticas educaciomais formuladas em nivem nacional e regional. (2006, p. 91)

Assim, uma nova mentalidade precisa ambientar as dicussões a respeito dessa disciplina, pois, ela se ressignificada pode propiciar aspectos ainda não explorados pelos curos de formação de professores.

\section{Referências}

AGOSTINI, Sandra; PAIM, Elison Antônio. Estágio: contribuições para a formação do professor de História. História e Ensino Laboratório de Ensino e História, Londrina, v.12, p.187-202, agosto 2006.

AMARAL, Maria do Carmo; IWAYA, Marilda. Estágio Supervisionado - Novas Possibilidades na Formação de Professores. In: NET0,José M. Arias(Org.).Dez Anos de Pesquisas em Ensino de História.VI Encontro Nacional de Pesquisadores de Ensino de História.Londrina,PR: AtritoArt, 2005, p.323-236, p.990.

ANDRÉ, Marli Eliza Dalmazo Afonso de. A etnografia da prática escola..Campinas, SP: Papirus, 1995.

BARREIR0, Iraíde Marques de Freitas e GEBRAN, Raimunda Abou. Prática de Ensino e Estágio Supervisionado na Formação de professores. São Paulo: Avercamp, 2006. 
BITTENCOURT, Circe (Org.). O Saber Histórico na Sala de Aula. $7^{a}$ ed. São Paulo: Contexto, 2002.

CAINELLI, Marlene Rosa. 0 lugar da Prática de Ensino na produção do saber escolar. In: SCHMIDT, Maria Auxiliadora Moreira dos Santos; CAINELLI, Marlene Rosa. III Encontro: Perspectivas do Ensino de História. Curitiba : Aos Quatro Ventos, p.143-148,1999.

DERNA, Pescuma; CASTILHO, Antônio Paulo Ferreira de. Projeto de pesquisa - O que é? Como fazer? : um guia para a sua elaboração. São Paulo: Olho D’Água, 2005.

DIONNE, Jean; LAVILLE, Christian. A Construção do Saber. Manual de metodologia de pesquisa em ciências humanas. Trad. Heloísa Monteiro e Francisco Settineri. Porto Alegre, RS: Artes Médicas Sul Ltda.; Belo Horizonte, MG: Editora UFMG, 1999

FAZENDA, Ivani Catarina Arantes et al; PICONEZ, Stela C. Bertholo (coord.). A Prática de Ensino e o Estágio Supervisionado. Campinas, SP. Papirus,2001

FAZENDA, Ivani Catarina Arantes. 0 Papel do Estágio nos cursos de Formação de professores. In: FAZENDA, Ivani Catarina Arantes et al; PICONEZ, Stela C. Bertholo (coord.). A Prática de Ensino e o Estágio Supervisionado. Campinas, SP. Papirus, 2001 GIESTA, Nágila Caporlingua. Professores de Licenciaturas: concepções sobre aprender: Disponível em: http://www.anped.org.br/reunioes/23/textos/0836t.PDF. Capturado em novembro de 2007.

LORENZI, Marlene G. Rego; CENZNE, Andréa N.; Montagner, Rosangela; CUNHA, Jorge L. da. Concepções do Ensino de História no Processo de Formação. In: SCHMIDT, Maria Auxiliadora Moreira dos Santos; CAINELLI, Marlene Rosa. III Encontro: Perspectivas do Ensino de História. Curitiba: Aos Quatro Ventos, p.67-75,1999.

LUDKE, Menga; ANDRÉ, Marli Eliza Dalmazo Afonso de. Pesquisa em educação: abordagens qualitativas. São Paulo: EPU,1986.

MONTEIR0, Ana Maria F.C. 0 Lugar da Prática de Ensino na Formação do Professor: Um espaço de socialização profissional. In: SCHMIDT, Maria Auxiliadora Moreira dos Santos; CAINELLI, Marlene Rosa. III Encontro: Perspectivas do Ensino de História. Curitiba: Aos Quatro Ventos, p.122-134, 1999.

A prática de ensino e a produção de saberes na escola. In: CANDAU (Org.). Didática, currículo e saberes escolares. 2 ed., RJ:DP \& A, 2002, p. 129-147. 200p.

OLIVEIRA, Vera Cristina de. 0 Estágio Curricular de Ensino de Alunos do Curso de 
História da UFSC: alguns elementos para compreensão de sua formação inicial para professor. In: NET0, José M. Arias(Org.).Dez Anos de Pesquisas em Ensino de História.VI Encontro Nacional de Pesquisadores de Ensino de História. Londrina, PR: AtritoArt, 2005, p.339-347, p.990.

PIMENTA, Selma Garrido. 0 Estágio na Formação de Professores: unidade teoria e prática? 6a ed., São Paulo: Cortez, 2005.200 p.

RANZI, Serlei M. F; MARTINS, Cláudia R.K. Profissão Docente: Formação e Prática de Professores de História no Ensino Médio. Revista do Laboratório de Ensino e História, Londrina, v.9, p.273-299, 2003.

RANZI, Serlei Maria Fischer. O Lugar da Prática de Ensino na Produção do Saber Escolar. III Encontro: Perspectivas do Ensino de História. Curitiba: Aos Quatro Ventos, p.135-142, 1999.

TIMBÓ, Isaíde Bandeira. Alternativa de intervenção social para o estágio supervisionado: minicursos em questão. Revista do Laboratório de Ensino e História, Londrina, v.12, p.123-140, 2006.

VILLALTA, Luiz Carlos. Dilemas da relação teoria e pratica na formação do professor de Historia: alternativas em perspectiva. Revista Brasileira de História. São Paulo, v.13, n²5/26, p.223-232, set.92/ago.93. 


\section{The Place of Teaching Practice, in the inicial formation of the history's teacher: \\ a study about the UNESP history's course, Assis's campus.}

\section{ABSTRACT}

This article has objective to present some considerations of a research accomplished the Education master's degree program of the Universidade Estadual de Londrina that reflects on the training of teachers of history. The literature indicates a dichotomy established in the Departments of History between the specific content of these disciplines and the pedagogias - usually the responsibility of the Education's faculty - it was done a reflection on the relation of these departments with the training of teachers. Special interest was given to the meaning that the discipline of Methodology and Practice of Teaching / Training is the training of teachers of history. For this we discuss the significance of this discipline in the course of the history of UNESP-Assis.

Key- words: teacher training, teaching pratice, traineeship. 